\title{
Zn and Fe Concentration Variations of Grain and Flag Leaf and the Relationship with NAM-G1 Gene in Triticum timopheevii (Zhuk.) Zhuk. ssp. timopheevii
}

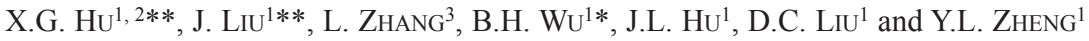 \\ ${ }^{1}$ Triticeae Research Institute, Sichuan Agricultural University, \\ Wenjiang 611130, Chengdu, Sichuan, P. R. China \\ ${ }^{2}$ Center of Wheat Research, Henan Institute of Science and Technology, \\ Xinxiang 453003, Henan, P. R. China \\ ${ }^{3}$ Department of Biology and Science, Sichuan Agricultural University, 625014 Ya'an, Sichuan, P. R. China \\ (Received 17 October 2016; Accepted 21 December 2016; \\ Communicated by I. Molnár)
}

\begin{abstract}
Grains of 12 accessions of Triticum timopheevii (Zhuk.) Zhuk. ssp. timopheevii (AAGG, $2 n=4 x=28)$ and one bread wheat cultivar Chinese Spring (CS) and one durum wheat cultivar Langdon (LDN) grown across two years were analyzed for grain iron $(\mathrm{Fe})$ and zinc $(\mathrm{Zn})$ concentrations. All the 12 tested T. timopheevii ssp. timopheevii genotypes showed significantly higher concentration of grain Fe and $\mathrm{Zn}$ than $\mathrm{CS}$ and LDN. Aboundant genetic variability of both the Fe and $\mathrm{Zn}$ concentrations was observed among the T. timopheevii ssp. timopheevii accessions, averagely varied from 47.06 to $90.26 \mathrm{mg} \mathrm{kg}^{-1}$ and from 30.05 to $65.91 \mathrm{mg} \mathrm{kg}^{-1}$, respectively. Their grain $\mathrm{Fe}$ and $\mathrm{Zn}$ concentrations between years exhibited a significantly positive correlation with the correlation coefficients $r=0.895$ and $r=0.891$, respectively, indicating the highly genetic stability. Flag leaf possessed twice or three times higher concentrations for both $\mathrm{Fe}$ and $\mathrm{Zn}$ than grain, and a significantly high positive correlation appeared between the two organs with $r=0.648$ for $\mathrm{Fe}$ and $r=0.957$ for $\mathrm{Zn}$ concentrations, respectively, suggesting flag leaves might be indirectly used for evaluating grain $\mathrm{Zn}$ and $\mathrm{Fe}$ contents. Significant correlations occurred between grain $\mathrm{Fe}$ and $\mathrm{Zn}$ concentrations, and between grain $\mathrm{Zn}$ concentration and the two agronomic traits of plant height and number of spikelets per spike. Both the concentrations were not related to seed size or weight as well as NAM-Gl gene, implying the higher grain $\mathrm{Fe}$ and $\mathrm{Zn}$ concentrations of T. timopheevii ssp. timopheevii species are not ascribed to concentration effects of seed and the genetic control of NAM-G1 gene. There might be some other biological factors impacting the grain's $\mathrm{Zn}$ and Fe concentrations. These results indicated T. timopheevii ssp. timopheevii species might be a promising genetic resource with high $\mathrm{Fe}$ and $\mathrm{Zn}$ concentrations for the biofortification of current wheat cultivars.
\end{abstract}

Keywords: T. timopheevii ssp. timopheevii, iron, zinc, $N A M-G 1$ gene, biofortification

\footnotetext{
*Corresponding author; E-mail: wubihua2005@126.com; Phone/Fax:+86 2882650350

**An equal contribution to this article.
} 


\section{Introduction}

It has been reported that micronutrient malnutrition, particularly deficiencies in Fe and Zn, afflicts a very large proportion of the world's people. The World Health Organization estimated that more than 2 billion people have deficiencies in $\mathrm{Zn}$ and Fe, resulting in overall poor health, anemia, increased morbidity and mortality rates, and low worker productivity (Hotz and Brown 2004; Welch and Graham 2004; Bouis 2007; Cakmak 2008; Salim-Ur-Rehman et al. 2010). Currently, the phenomena which are termed "hidden hunger" (FAO 2002), generally occur in developing countries, where most people rely on cereal grain as their staple food.

Bread wheat (Triticum aestivum L.) is one of the most important staple food crops, providing $28 \%$ of world's edible dry matter (Cakmak 2008). So, the composition and nutritional quality of wheat grain have a significant impact on human health and wellbeing worldwide (Chatzav et al. 2010; Wang et al. 2011). In the past, a great effort has been made for improving wheat grain yield and resistance to leaf diseases (He et al. 2004). However, little attention was given to micromineral nutritional quality, resulting in most of modern elite wheat varieties having lower grain Fe and $\mathrm{Zn}$ concentrations (Cakmak 2008; Joshi et al. 2010). Thus, biofortification of wheat grain through genetic manipulation has been proposed as the best approach for combating micronutrient malnutrition.

Sufficient variability for Fe and $\mathrm{Zn}$ concentrations is not available in the cultivated germplasm of wheat, limiting options for breading wheat with high concentrations and bioavailability of Fe and $\mathrm{Zn}$ (Cakmak et al. 2004). Whereas, several wild species have been reported possessing higher grain Fe and Zn concentrations (Chhuneja et al. 2006; Chatzav et al. 2010). Wang et al. (2011) reported wheat-Aegilops disomic addition lines showed high Fe and Zn concentrations. Neelam et al. (2011) discovered that introgression of group 4 and 7 chromosomes of Ae. peregrina (Hack.) Maire \& Weill (UP ${ }^{P} S^{P} S^{P}$, $2 n=4 x=28$ ) in wheat enhanced grain Fe and $\mathrm{Zn}$ concentrations. Consequently, these results are undoubtedly encouraging to screen and utilize wild species for improving $\mathrm{Fe}$ and $\mathrm{Zn}$ concentrations of cultivated wheat.

T. timopheevii $(2 \mathrm{n}=4 \mathrm{x}=28$, AAGG) is an ancient-related species cultivated (Wan et al. 2002). Several useful genes for current wheat breeding were found in T. timopheevii, such as the traits for wheat T-type cytoplasmic male sterility (Sun et al. 2001), powdery mildew (Jorgensen and Jensen 1973). Our previous study discovered T. timopheevii ssp. timopheevii species had NAM-G1 genes, being highly similar to the previously published functional NAM-B1 gene of T. dicoccoides (Körn. ex Asch. \& Graebn.) Schweinf. (AABB, $2 \mathrm{n}=4 \mathrm{x}=28$ ). And, the tested $N A M$ - $G 1$ relative expression quantities were significantly positively correlated with grain protein content (GPC) of the $T$. timopheevii ssp. timopheevii accessions (Hu et al. 2013). The $N A M-B 1$ gene can enhance the transfer of nutrients from the leaves to the grain, which led to an increase in grain $\mathrm{Zn}$ and Fe concentration (Uauy et al. 2006b). However, it is unclear that the variability of grain $\mathrm{Fe}$ and $\mathrm{Zn}$ concentrations and the relationship between them and NAM-G1 gene in T. timopheevii ssp. timopheevii. This study is to identify genetic variation for grain $\mathrm{Fe}$ 
and $\mathrm{Zn}$ concentrations in T. timopheevii ssp. timopheevii, and to analyze correlation among grain $\mathrm{Fe}$ and $\mathrm{Zn}$ concentrations with agronomic traits and $N A M-G 1$ gene, in order to exploit the potential genetic resource with high Fe and $\mathrm{Zn}$ concentrations for biofortification program of elite bread and durum wheat cultivars, and better understand the $N A M-G 1$ gene function as well as characteristics of grain Fe and $\mathrm{Zn}$ concentrations in T. timopheevii ssp. timopheevii.

\section{Materials and Methods}

\section{Plant materials}

The plant materials comprised 12 accessions T. timopheevii ssp. timopheevii were kindly provide by the NPGS (http://www.ars-grin.gov), as well as the two wheat cultivars of T. aestivum cv. Chinese Spring (CS, $2 \mathrm{n}=6 \mathrm{x}=42$, AABBDD) and T. durum cv. Langdon (LDN, $2 \mathrm{n}=4 \mathrm{x}=28$, AABB) used as reference were obtained from Triticeae Research Institute, Sichuan Agricultural University, China (Table S1*). All of the tested materials were grown in the experimental station of the Triticeae Research Institute, Sichuan Agricultural University for two consecutive seasons of 2009-2010 and 2010-2011. Grain were harvested and threshed from each material at physiological maturity.

\section{Determination of $\mathrm{Fe}$ and $\mathrm{Zn}$ concentration in grain}

Whole-grain samples were washed with $0.1 \mathrm{M} \mathrm{HCl}$ and dried to constant weight at $80^{\circ} \mathrm{C}$. Dried grains of each material were ground to powder using non-rust steel miller, and then the powders were placed in a clean plastic bag for analysis. The powdered grains $(0.5 \pm 0.0005 \mathrm{~g})$ were placed into each polytetrafluoroethylene (PTFE) beaker, to which a $\mathrm{HNO}_{3}: \mathrm{HClO}_{4}(4: 1)$ diacid mixture was added. The samples were digested till only dry white residues were obtained, and then made volume required. Meanwhile, blank and standard samples were added each time for reference. Grain Fe and $\mathrm{Zn}$ concentrations expressed as $\mathrm{mg} \mathrm{kg}^{-1}$ dry weight were analyzed by an atomic absorption spectrophotometer (AA6100, Shimadzu, Japan). Three replications were performed to minimize the error during analysis.

\section{Determination of Fe and Zn concentration in flag leaf}

In seasons of 2010-2011, flag leaves from 12 accessions T. timopheevii ssp. timopheevii were collected during the stage from heading to anthesis. According to the method of Rawat et al. (2009b), the leaves were washed thoroughly with $0.1 \mathrm{M} \mathrm{HCl}$, dried at $80{ }^{\circ} \mathrm{C}$ for $8 \mathrm{~h}$ in oven prior to digestion. Dried leaf samples were then digested, using the above method for grain. Leaf $\mathrm{Fe}$ and $\mathrm{Zn}$ concentrations with three replications were also analyzed by AA6100.

*Further details about the Electronic Supplementary Material (ESM) can be found at the end of the article. 


\section{Investigation of agronomic traits}

The four agronomic traits including plant height, number of tiller per plant, number of spikelet per spike and thousand-kernel weight (TKW) were investigated through traditional method from 12 accessions T. timopheevii ssp. timopheevii in seasons of 20102011. The grain volume made up of the longest, widest and thickest sizes from 30 seeds per accession was determined through a vernier caliper.

\section{The expression levels of NAM-G1 genes}

The relative expression levels of $N A M-G 1$ genes from the 12 T. timopheevii ssp. timopheevii accessions were completed in our prior research (Hu et al. 2013). In that study, the actin gene used as reference, qRT-PCR of $N A M-G 1$ gene was performed with the $\mathrm{iQ}^{\mathrm{TM}} 5$ Real-Time PCR Detection Systems (Bio-Rad, CA, USA). The relative quantity of $N A M-G 1$ gene was presented as normalized linearization value using $2^{-\Delta \Delta \mathrm{Ct}}$ method. Those results showed that the relative expression levels of $N A M-G 1$ genes were significantly different $(\mathrm{F}=85.25, P<0.01)$, ranging from 0.63 to 1.41 .

\section{Statistical analysis}

Statistical analyses were performed using SPSS version 17.0 for Windows (SPSS Inc., Chicago, IL, USA), including computation of mean performance, analysis of variance, correlation and regression analyses. Means were compared by the least significant difference test. Pearson's correlation was calculated to evaluate the correlations among variables.

\section{Results}

Stability for grain Fe and Zn concentrations in T. timopheevii ssp. timopheevii across years

Grain Fe and Zn concentrations in the 12 tested T. timopheevii ssp. timopheevii accessions between Year 1 (2009-2010) and Year $2(2010-2011)$ exhibited a significantly positive correlation $(P<0.01)$ (Fig. 1), with high correlation coefficients $\mathrm{r}=0.895$ and $\mathrm{r}=0.891$, respectively. It revealed both the $\mathrm{Fe}$ and $\mathrm{Zn}$ concentrations in the T. timopheevii ssp. timopheevii lines were highly consistent across years, indicating the highly environmental stability of the grain $\mathrm{Fe}$ and $\mathrm{Zn}$ contents.

Variability of grain Fe and Zn concentrations among T. timopheevii ssp. timopheevii accessions

The genetic variability for $\mathrm{Fe}$ and $\mathrm{Zn}$ concentrations in the 12 accessions of T. timopheevii ssp. timopheevii, two wheat cultivars Chinese Spring (CS) and Langdon (LDN) grown across the two experimental years, was shown in Table S1. Grain Fe concentrations of the 

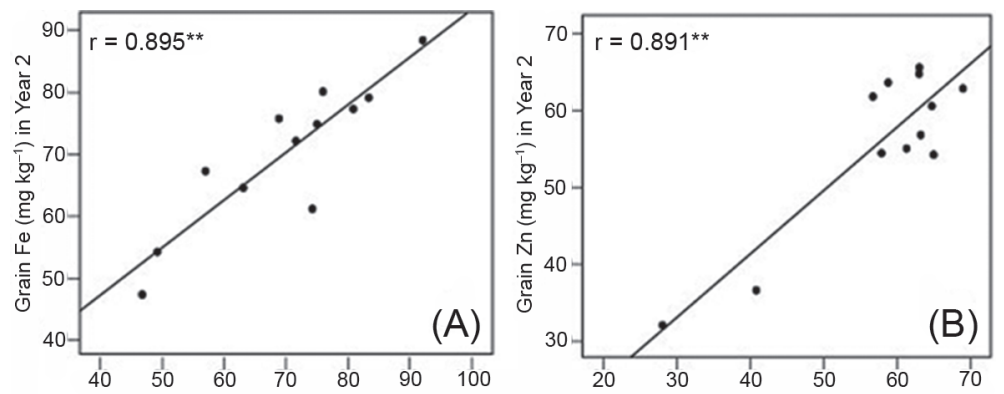

Figure 1. Correlations of grain Fe (A) and Zn (B) concentrations of T. timopheevii ssp. timopheevii species between Year 1 (2009-2010) and Year 2 (2010-2011)

12 T. timopheevii ssp. timopheevii accessions averaged $69.83 \mathrm{mg} \mathrm{kg}^{-1}$ and $70.21 \mathrm{mg} \mathrm{kg}^{-1}$ in Year 1 (2009-2010) and Year 2 (2010-2011), respectively. Meanwhile, the grain Zn concentrations averaged $57.60 \mathrm{mg} \mathrm{kg}^{-1}$ and $55.71 \mathrm{mg} \mathrm{kg}^{-1}$ in Year 1 and Year 2, respectively. By contrast, the grain micronutrient concentrations of bread and durum wheat cultivars were quite low. CS had Fe about 28.23 and $29.65 \mathrm{mg} \mathrm{kg}^{-1}$, and $\mathrm{Zn}$ about 21.12 and $23.14 \mathrm{mg} \mathrm{kg}^{-1}$ in the two tested years, respectively. Likewise, LDN was with Fe about 27.16 and $26.34 \mathrm{mg} \mathrm{kg}^{-1}$, and $\mathrm{Zn}$ about 20.58 and $22.45 \mathrm{mg} \mathrm{kg}^{-1}$. Analysis of variance further indicated that all the T. timopheevii ssp. timopheevii accessions in Fe and Zn concentrations were significantly higher than bread wheat CS and the durum wheat LDN in the two years (Table S1, Table 1).

The grain Fe concentrations among the 12 tested T. timopheevii ssp. timopheevii accessions varied from 46.76 to $92.11 \mathrm{mg} \mathrm{kg}^{-1}$ and 47.36 to $88.41 \mathrm{mg} \mathrm{kg}^{-1}$ in Year 1 and Year 2 , respectively, with an average variation of the two years from $47.06 \mathrm{mg} \mathrm{kg}^{-1}$ to 90.26 $\mathrm{mg} \mathrm{kg}^{-1}$. Meanwhile, the grain $\mathrm{Zn}$ concentrations ranged from 28.04 to $68.96 \mathrm{mg} \mathrm{kg}^{-1}$ and 32.06 to $65.60 \mathrm{mg} \mathrm{kg}^{-1}$ in Year 1 and Year 2, respectively, with an average variation of the two years from $30.05 \mathrm{mg} \mathrm{kg}^{-1}$ to $65.91 \mathrm{mg} \mathrm{kg}^{-1}$. Analysis of variance showed the significant difference for both the grain Fe and $\mathrm{Zn}$ concentrations among the materials (Table S1, Table 1). And, the ten genotypes PI266850, PI119442, PI221421, PI94761, PI190974, PI272523, PI251017, PI94760, PI272530, CItr15205 possessed both higher Fe and Zn

Table 1. Analysis of variance for grain $\mathrm{Fe}$ and $\mathrm{Zn}$ concentrations across the two years

\begin{tabular}{|l|c|c|c|c|c|}
\hline \multirow{2}{*}{ Source of variation } & \multirow{2}{*}{$\begin{array}{c}\text { Degree } \\
\text { of freedom }\end{array}$} & \multicolumn{4}{|c|}{ Mean sum of square } \\
\cline { 3 - 6 } & & Year 1 (2009-2010) & \multicolumn{2}{c|}{ Year 2 (2010-2011) } \\
\cline { 3 - 6 } & & Grain Fe & Grain Zn & Grain Fe & Grain Zn \\
\hline Replication & 2 & 5.25 & 0.02 & 1.77 & 2.12 \\
\hline Accesion/cultivar & 13 & $1177.74^{* *}$ & $879.47^{* *}$ & $1055.75^{* *}$ & $724.81^{* *}$ \\
\hline Error & 26 & 2.94 & 0.22 & 4.01 & 0.66 \\
\hline
\end{tabular}

Note: **significant at $P=0.01$ level. 
contents, while the two lines PI282932 and PI282933 had both lower Fe and Zn contents. Apparently, T. timopheevii ssp. timopheevii species had abundant genetic resources with high Fe and Zn concentration, which could be selected for crosses with bread and durum wheat cultivars for their Fe and $\mathrm{Zn}$ biofortifications.

\section{Correlations between grain and flag leaf for Fe and Zn concentrations}

In order to confirm whether some associations existed between grain and leaf for Fe and $\mathrm{Zn}$ concentrations, the $\mathrm{Fe}$ and $\mathrm{Zn}$ concentrations in flag leaves of the $12 \mathrm{~T}$. timopheevii ssp. timopheevii accessions were examined during the stage from heading to anthesis in Year 2 (2010-2011). It was showed that the flag leaves had twice to three times higher Fe and $\mathrm{Zn}$ concentrations than grains. Moreover, significant positive correlations were found between leaf and grain for both $\mathrm{Zn}$ with a very high correlation coefficient $\mathrm{r}=0.957$ $(P<0.01)$ and Fe with $\mathrm{r}=0.648(P<0.05)$ in the tested accessions (Fig. 2). These indicated both the $\mathrm{Fe}$ and $\mathrm{Zn}$ contents in grains might be availably forecasted by those in flag leaves.
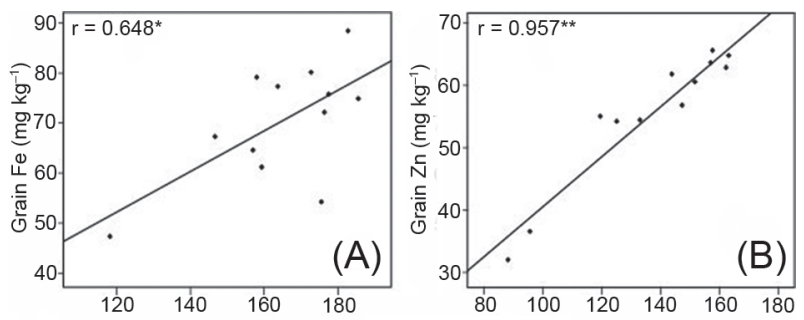

Figure 2. Correlation between leaf and grain micronutrients (Fe (A) and $\mathrm{Zn}(\mathrm{B}))$ of T. timopheevii ssp. timopheevii species in Year 2 (2010-2011)

Correlations between grain Fe and Zn concentrations as well as between them and agronomic traits

The relationships between concentrations of the two mineral elements and agronomic traits besides that between grain $\mathrm{Fe}$ and $\mathrm{Zn}$ concentrations of $T$. timopheevii ssp. timopheevii accessions were tested in the season of Year 2 (2010-2011). As shown in Table 2, there was significantly positive correlation between grain Fe and $\mathrm{Zn}$ concentrations $(\mathrm{r}=0.638, P<0.05)$. No obvious relationship existed between $\mathrm{Zn}$ or Fe concentration and the two agronomic traits including tillers per plant and seed size (grain volume or thousand-kernel weight), which indicated the two mineral elements' concentrations might be not disturbed by seed size. However, positive correlations between the grain $\mathrm{Zn}$ concentration and the two agronomic traits of plant height and spikelets per spike were discovered with coefficients 0.678 and 0.588 at 0.05 level, respectively. Particularly, no relationship was observed between grain Fe concentration and all the tested agronomic traits. 
Table 2. Pearson's correlations among grain Fe and $\mathrm{Zn}$ concentrations and five agronomic traits

in 12 T. timopheevii ssp. timopheevii accessions grown in the season of 2010-2011 (Year 2)

\begin{tabular}{|c|c|c|c|c|c|c|}
\hline & $\mathrm{Zn}$ & Plant height & Tillers per plant & Spikelets per spike & Grain volume & TKW \\
\hline $\mathrm{Zn}$ & & $0.678^{*}$ & 0.103 & $0.588^{*}$ & 0.289 & 0.252 \\
\hline $\mathrm{Fe}$ & $0.638^{*}$ & 0.13 & 0.317 & 0.424 & -0.221 & 0.134 \\
\hline
\end{tabular}

Note: *significant at $P=0.05$ level.

\section{Correlations between the concentration of grain $\mathrm{Fe}$ and $\mathrm{Zn}$} and the expression level of NAM-G1 gene

In Year 1 (2009-2010), the correlation coefficients of the grain Fe and $\mathrm{Zn}$ concentrations and the gene expression level were $r=-0.022$ and $r=0.174$, and in Year 2 (2010-2011), $\mathrm{r}=0.141, \mathrm{r}=0.016$, respectively (Figs S1, S2). Apparently, not only grain Fe but also grain $\mathrm{Zn}$ concentration was not relevant with the expression level of NAM-G1 gene.

\section{Discussion}

T. dicoccoides was commonly recognized as the most promising genetic resource (Cakmak et al. 2004; Chatzav et al. 2010). It is rich in micronutrients such as Fe and Zn (Chhuneja et al. 2006; Chatzav et al. 2010; Neelam et al. 2011). However, the effective variability of $\mathrm{Fe}$ and $\mathrm{Zn}$ concentrations in T. timopheevii ssp. timopheevii has little reported to date. In this study, the results across the two experimental years showed the 12 tested T. timopheevii ssp. timopheevii accessions possessed significantly higher grain Fe and $\mathrm{Zn}$ concentrations than bread and durum wheat (Table S1), of them, the lines PI266850 and PI119442, possessed the highest Fe and Zn contents for $90.26 \mathrm{mg} \mathrm{kg}^{-1}$ and $65.91 \mathrm{mg}$ $\mathrm{kg}^{-1}$, respectively. Moreover, a vast majority of them had both higher Fe and $\mathrm{Zn}$ concentrations. Correlation analyses further detected the significantly positive correlation between the concentrations of grain $\mathrm{Fe}$ and $\mathrm{Zn}$ in the T. timopheevii ssp. timopheevii accessions (Table 2), which agreed with previous studies of a number of germplasm from wild and modern wheat and spelt wheat (Morgounov et al. 2007; Chatzav et al. 2010; GomezBecerra et al. 2010a, b). This illustrated the tested T. timopheevii ssp. timopheevii materials were genetically stable for controlling grain Fe and $\mathrm{Zn}$ concentrations.

Morgounov et al. (2007) reported that there is a significant negative correlation between the concentrations of grain Fe and $\mathrm{Zn}$ and the grain yield in modern cultivars. But, there seems to be no correlation between thousand-kernel weight (TKW) and grain Zn content in adapted wheat lines (Velu et al. 2012). Gomez-Becerra et al. (2010b) discovered most of genotypes were not only with high grain $\mathrm{Zn}$ and Fe concentrations but also high seed weight in $T$. dicoccoides, considering no concentration effect due to small grain size. Similar to the previous reports by Cakmak et al. (2004) and Velu et al. (2012) who discovered no negative linkage of grain $\mathrm{Zn}$ and Fe with grain yield, our study also indicated the $\mathrm{Fe}$ and $\mathrm{Zn}$ concentrations were not correlative with both the seed volume and thousand-kernel weight (TKW) in 12 T. timopheevii ssp. timopheevii accessions 
(Table 2). Therefore, it is believable that T. timopheevii ssp. timopheevii might be one of promising genetic resources for breeding iron- and zinc-fortified wheat via traditional cross and the grain yield might be not affected.

Not only grain $\mathrm{Fe}$ and $\mathrm{Zn}$ concentrations displayed the very close positive correlation in a number of germplasm resources, but also they had some same characteristics like significant positive correlation with grain protein content, as well as negative correlation with the traits of glutenin content, plant height and grain number per $\mathrm{m}^{2}$ (Oury et al. 2006; Morgounov et al. 2007). Hence, it was inferred that physiological and genetic factors involved in $\mathrm{Zn}$ and Fe deposition in the seeds are same or very similar, or the alleles for $\mathrm{Zn}$ and Fe deposition in the grain co-segregate or pleiotropic (Velu et al. 2014). In the present research, the grain $\mathrm{Zn}$ concentration was significantly related to the agronomic traits such as plant height and number of spikelets per plant of T. timopheevii ssp. timopheevii (Table 2), while no obvious relationship was observed between grain Fe concentration and all of the tested agronomic traits. These diverse results might be resulted from different experimental materials. On the other side, the genetic systems controlling grain $\mathrm{Fe}$ and $\mathrm{Zn}$ concentrations or their physiologically and biochemically metabolic systems might be relevant but of some discrimination. Our study also discovered that the flag leaves had twice to three times higher Fe and $\mathrm{Zn}$ concentrations than grains, as well as both the concentrations in the flag leaves were significantly positively correlated with those in grains of the 12 tested T. timopheevii ssp. timopheevii accessions (Fig. 2), which agreed with the result of Aegilops species reported by Rawat et al. (2009a, b). These implied flag leaves could be indirectly used for evaluating grain $\mathrm{Zn}$ and Fe contents in the breeding programs, which would benefit the seeds with both high Fe and $\mathrm{Zn}$ contents to keep from being ground for examining the mineral element. And, it should be feasible that the flag leaves used to do qRT-PCR expression analysis for investigating the genes controlling grain $\mathrm{Fe}$ and $\mathrm{Zn}$ concentrations.

Many different transporters for the uptake of $\mathrm{Fe}, \mathrm{Mn}, \mathrm{Cu}$ and $\mathrm{Zn}$ have been identified, such as IRTI (iron-regulated transporter 1) encoding the major Fe transporter at the root surface. Over-expression of OSIRT1 led to increase both Fe and $\mathrm{Zn}$ accumulation in rice (Lee and An 2009). In addition, the ancestral $N A M-B 1$ gene of the high protein locus $G p c-B 1$ belonging to a simple Mendelian inheritance (Distelfeld et al. 2004) being located on 6BS in $T$. dicoccoides, could simultaneously increase remobilization of mineral $\mathrm{Fe}$ and $\mathrm{Zn}$ nutrients and $\mathrm{N}$ elements from leaves to seeds, resulting in $\mathrm{Fe}, \mathrm{Zn}$ and protein accumulation in seeds, and at the same time, shorten the filling stage leading to decreasing seed size. So, this gene is considered as being pleiotropism (Uauy et al. 2006a; Waters et al. 2009). Our previous study discovered that the ancestral $N A M-G 1$ genes existing in all the 12 tested T. timopheevii ssp. timopheevii accessions, were highly similar in molecular structures to the previously published functional $N A M-B 1$ gene. In addition the qRT-PCR levels of $N A M-G 1$ alleles are highly related, as well as their sequence variations in both nucleotide and amino acid also probably relevant to the genetic adversity of grain protein concentration in the T. timopheevii ssp. timopheevii lines (Hu et al. 2013). The current study showed that both the grain Fe and Zn concentrations were not obviously associated with the expression levels of the NAM-G1 genes (Figs S1, S2). Some evi- 
dences have shown that grain $\mathrm{Fe}$ and $\mathrm{Zn}$ are quantitatively inherited traits in wheat (Trethowan et al. 2005). It is well known that protein is one kind of organic compounds, whereas Fe and $\mathrm{Zn}$ are inorganic mineral elements. So, there are many differences not only in physical and chemical properties but also in physiological and biochemical properties between these two kinds of substances, which would result in being different in their anabolism as well as catabolism, intake as well as translation, etc. in different plants. Thus, there might be other biological factors impacting the grain's $\mathrm{Zn}$ and Fe concentrations. And, further research in this area would be needed.

\section{Acknowledgements}

We wish to thank the anonymous reviewers for helpful comments that improved the manuscript. This research was supported by the Specialized Research Fund for the Doctoral Program of Higher Education of China (No. 20125103110003) and by Education Committee Accented Term in Sichuan Province and by the International Cooperation Program of Science \& Technology Department of Sichuan Province (No. 2015HH0021).

\section{References}

Bouis, H.E. 2007. The potential of genetically modified food crops to improve human nutrition in developing countries. J. Dev. Stud. 43:79-96.

Cakmak, I., Torun, A., Millet, E., Feldman, M., Fahima, T., Korol, A., Nevo, E., Braun, H.J., Özkan, H. 2004. Triticum dicoccoides: an important genetic resource for increasing zinc and iron concentration in modern cultivated wheat. Soil Sci. Plant Nutr. 50:1047-1054.

Cakmak, I. 2008. Enrichment of cereal grains with zinc: Agronomic or genetic biofortification. Plant Soil 302:1-17.

Chatzav, M., Peleg, Z., Ozturk, L., Yazici, A., Fahima, T., Cakmak, I., Saranga, Y. 2010. Genetic diversity for grain nutrients in wild emmer wheat: potential for wheat improvement. Ann. Bot. 105:1211-1220.

Chhuneja, P., Dhaliwal, H.S., Bains, N.S., Singh, K. 2006. Aegilops kotschyi and Aegilops tauschii as sources for higher levels of grain iron and zinc. Plant Breeding 125:529-531.

Distelfeld, A., Uauy, C., Olmos, S., Schlatter, A.R., Dubcovsky, J., Fahima, T. 2004. Microcolinearity between a 2-cM region encompassing the grain protein content locus $G p c-6 B 1$ on wheat chromosome $6 \mathrm{~B}$ and a 350 $\mathrm{kb}$ region on rice chromosome 2. Funct. Integr. Genomics 4:59-66.

FAO 2002. The state of food insecurity in the world. Rome, Italy.

Gomez-Becerra, H.F., Erdem, H., Yazici, A., Tutus, Y., Torun, B., Ozturk, L., Cakmak, I. 2010a. Grain concentrations of protein and mineral nutrients in a large collection of spelt wheat grown under different environments. J. Cereal Sci. 52:342-349.

Gomez-Becerra, H.F., Yazici, A., Ozturk, L., Budak, H., Peleg, Z., Morgounov, A., Fahima, T., Saranga, Y., Cakmak, I. 2010b. Genetic variation and environmental stability of grain mineral nutrient concentrations in Triticum dicoccoides under five environments. Euphytica 171:39-52.

He, Z.H., Yang, J., Zhang, Y., Quail, K.J., Peña, R.J. 2004. Pan bread and dry white Chinese noodle quality in Chinese winter wheats. Euphytica 139:257-267.

Hotz, C., Brown, K.H. 2004. Assessment of the risk of zinc deficiency in populations and options for its control. Food Nutr. Bull. 25:194-204.

Hu, X.G., Wu, B.H., Liu, D.C., Wei, Y.M., Gao, S.B., Zheng, Y.L. 2013. Variation and their relationship of NAM-G1 gene and grain protein content in Triticum timopheevii Zhuk. J. Plant Physiol. 170:330-337.

Jorgensen, J.H., Jensen, C.J. 1973. Gene Pm6 for resistance to powdery mildew in wheat. Euphytica 22:423. 
Joshi, A.K., Crossa, J., Arun, B., Chand, R., Trethowan, R., Vargas, M., Ortiz-Monasterio, I. 2010. Genotype $\times$ environment interaction for zinc and iron concentration of wheat grain in eastern Gangetic Plains of India. Field Crop. Res. 116:268-277.

Lee, S., An, G. 2009. Over-expression of OsIRT1 leads to increased iron and zinc accumulations in rice. Plant Cell Envir. 32:408-416.

Morgounov, A., Gómez-Becerra, H.F., Abugalieva, A., Dzhunusova, M., Yessimbekova, M., Muminjanov, H., Zelenskiy, Y., Ozturk, L., Cakmak, I. 2007. Iron and zinc grain density in common wheat grown in Central Asia. Euphytica 155:193-203.

Neełam, K., Rawat, N., Tiwari, V.K., Kumar, S., Chhuneja, P., Singh, K., Randhawa, G.S., Dhaliwal, H.S. 2011. Introgression of group 4 and 7 chromosomes of Ae. peregrina in wheat enhances grain iron and zinc density. Mol. Breeding 28:623-634.

Oury, F.X., Leenhardt, F., Rémésy, C., Chanliaud, E., Duperrier, B., Balfourier, F., Charmet, G. 2006. Genetic variability and stability of grain magnesium, zinc and iron concentrations in bread wheat. Eur. J. Agron. 25:177-185.

Rawat, N., Tiwari, V.K., Neelam, K., Randhawa, G.S., Chhuneja, P., Singh, K., Dhaliwal, H.S. 2009a. Development and characterization of Triticum aestivum wheat-Aegilops kotschyi amphiploids with high grain iron and zinc contents. Plant Genet. Resour. 7:271-280.

Rawat, N., Tiwari, V.K., Singh, N., Randhawa, G.S., Singh, K., Chhuneja, P., Dhaliwal, H.S. 2009b. Evaluation and utilization of Aegilops and wild Triticum species for enhancing iron and zinc content in wheat. Genet. Resour. Crop Evol. 56:53-64.

Salim-Ur-Rehman., Huma, N., Tarar, O.M., Shah, W.H. 2010. Efficacy of non-heme iron fortified diets: a review. Crit. Rev. Food Sci. Nutr. 50:403-413.

Sun, L., Yao, F., Li, C., Li, L., Liu, B., Gao, Q. 2001. RAPD analysing of CMS-T, K, V mtDNAs and cloning of mtDNA fragments associated with CMS-K in wheat. Acta Agrono. Sinica 27:144-148.

Trethowan, R.M., Reynolds, M., Sayre, K., Ortiz-Monasterio, I. 2005. Adapting wheat cultivars to resource conserving farming practices and human nutritional needs. Ann. Appl. Biol. 146:405-413.

Uauy, C., Brevis, J.C., Dubcovsky, J. 2006a. The high grain protein content gene $G p c-B 1$ accelerates senescence and has pleiotropic effects on protein content in wheat. J. Exp. Bot. 57:2785-2794.

Uauy, C., Distelfeld, A., Fahima, T., Blechl, A., Dubcovsky, J. 2006b. A NAC gene regulating senescence improves grain protein, zinc, and iron content in wheat. Science 314:1298-1301.

Velu, G., Singh, R.P., Huerta-Espino, J., Peña, R.J., Arun, B., Mahendru-Singh, A., Yaqub Mujahid, M., Sohu, V.S., Mavi, G.S., Crossa, J., Alvarado, G., Joshi, A.K., Pfeiffer, W.H. 2012. Performance of biofortified spring wheat genotypes in target environments for grain zinc and iron concentrations. Field Crop. Res. 137:261-267.

Velu, G., Ortiz-Monasterio, I., Cakmak, I., Hao, Y., Singh, R.P. 2014. Biofortification strategies to increase grain zinc and iron concentrations in wheat. J. Cereal Sci. 59:365-372.

Wan, Y., Wang, D., Shewry, P.R., Halford, N.G. 2002. Isolation and characterization of five novel high molecular weight subunit of glutenin genes from Triticum timopheevi and Aegilops cylindrica. Theor. Appl. Genet. 104:828-839.

Wang, S., Yin, L., Tanaka, H., Tanaka, K., Tsujimoto, H. 2011. Wheat-Aegilops chromosome addition lines showing high iron and zinc contents in grains. Breeding Sci. 61:189-195.

Waters, B.M., Uauy, C., Dubcovsky, J., Grusak, M.A. 2009. Wheat (Triticum aestivum) NAM proteins regulate the translocation of iron, zinc, and nitrogen compounds from vegetative tissues to grain. J. Exp. Bot. 60:4263-4274.

Welch, R.M., Graham, R.D. 2004. Breeding for micronutrients in staple food crops from a human nutrition perspective. J. Exp. Bot. 55:353-364. 


\section{Electronic Supplementary Material (ESM)}

Electronic Supplementary Material (ESM) associated with this article can be found at the website of CRC at http://www.akademiai.com/content/120427/

Electronic Supplementary Table S1. Grain Fe and Zn concentrations of 12 accessions of T. timopheevii ssp. timopheevii and the two reference cultivars of Chinese Spring (CS) and durum Langdon (LDN) across two years

Electronic Supplementary Figure S1. Correlation between the concentration of grain Fe (A) and $\mathrm{Zn}(\mathrm{B})$ and the expression level of NAM-G1 gene of T. timopheevii ssp. timopheevii species in Year 1 (2009-2010)

Electronic Supplementary Figure S2. Correlation between NAM-G1 normalized expression and grain micronutrients (Fe (A) and Zn (B)) of T. timopheevii ssp. timopheevii species in Year 2 (2010-2011) 